\title{
Effects of L-lysine/L-arginine on the Physicochemical Properties and Quality of Sodium-Reduced and Phosphate-Free Pork Sausage
}

\author{
Yadong Zheng, Peng Xu, Shiyi Li, Xiaoxu Zhu, Conggui Chen, Cunliu Zhou* \\ School of Food Science and Engineering, Hefei University of Technology, Hefei, China
}

Email address:

zhouc14@hfut.edu.cn (Cunliu Zhou)

${ }^{*}$ Corresponding author

To cite this article:

Yadong Zheng, Peng Xu, Shiyi Li, Xiaoxu Zhu, Conggui Chen, Cunliu Zhou. Effects of L-lysine/L-arginine on the Physicochemical Properties and Quality of Sodium-Reduced and Phosphate-Free Pork Sausage. International Journal of Nutrition and Food Sciences. Vol. 6, No. 1, 2017, pp. 12-18. doi: 10.11648/j.ijnfs.20170601.13

Received: November 17, 2016; Accepted: December 1, 2016; Published: January 3, 2017

\begin{abstract}
This paper investigated the effects of L-lysine (Lys)/L-arginine (Arg) on the physicochemical and quality characteristics of sodium-reduced and phosphate-free pork sausage. The results showed that the addition of Lys/Arg decreased cooking loss (CL), but increased water holding capacity (WHC) and textural parameters (hardness, cohesiveness and chewiness) of pork sausage. The addition of Lys/Arg caused the decrease in $L^{*}$ values and $b^{*}$ values, and increase in $a^{*}$ values, compared with the control. The sausage treated with Lys/Arg had better sensory color, flavor, taste and slice traits, but lower P and Na content than the commercial one in China. Also, Lys- or Arg-treatment was conducive to the formation of dense and uniform three-dimensional network. The results suggest that Lys/Arg has a potential in the manufacture of pork sausage.
\end{abstract}

Keywords: L-lysine (Lys), L-arginine (Arg), Quality Characteristics, Physicochemical Property, Pork Sausage

\section{Introduction}

$\mathrm{NaCl}$ and food grade phosphates are currently the main additives for the improvement of the water holding capacity, juiciness and texture of meat products [1-3]. However, studies have shown that excessive intake of sodium $(\mathrm{Na})$ and phosphorus (P) can cause a series of health problems [4]. Moreover, a reduction in $\mathrm{NaCl}$ and phosphates can lead to a sharp decrease in the functional properties of meat products $[1,5]$. Therefore, searching for ingredients that can compensate for the negative effects caused by reducing $\mathrm{NaCl} /$ phosphate amount is one of the most important ways to develop sodium-reduced and phosphate-free meat products.

Recently, both L-lysine (Lys) and L-arginine (Arg), as an alternative of phosphates, have been demonstrated to improve the binding water capacity and texture of pork sausage with $2.5 \mathrm{~g} \mathrm{NaCl} / 100 \mathrm{~g}$, and to enhance the quality of frozen white shrimps [6]. Also, Lys is reported to remove the defects caused by replacement of $\mathrm{NaCl}$ with $\mathrm{KCl}$ [7]. Moreover, both Lys and Arg have been approved for use as a food flavoring essence and spice in China [8-9]. Theoretically, both Lys and
Arg may be used to prepare sodium-reduced and phosphate-free meat products without the loss of qualities. However, information is scant about the effects of Lys/Arg on the physicochemical and quality properties of sodium-reduced and phosphate-free meat products.

This study evaluated the effects of Lys/Arg on the physicochemical and sensory properties of cooked pork sausages with $25 \%$ replacement of $\mathrm{NaCl}$ with $\mathrm{KCl}$. Moreover, phosphate compound was not used under the present conditions.

\section{Materials and Methods}

\subsection{Materials}

L-Lysine (Lys) and L-arginine (Arg) were purchased from Shanghai Juyuan Biotechnology Co., Ltd. (Shanghai, China). Sodium chloride $(\mathrm{NaCl})$ and potassium chloride $(\mathrm{KCl})$ were purchased from Dongxing Salt Chemical Co., Ltd. (Dingyuan, Zhejiang Province, China). Sodium tripolyphosphate and sodium hexametaphosphate were 
purchased from Tianjin Guangfu Fine Chemical Research Institute (Tianjin, China), sodium pyrophosphate was purchased from Wuxi Zhanwang Chemical Co., Ltd. (Wuxi, China). All chemicals used were reagent grade and used as received.

Pork and pork back fat (three batches) were purchased from a local Hypermarket of the Carrefour Group (Hefei, China). The required amount of frozen pork legs and back fat was thawed for $24 \mathrm{~h}$ at $2-4^{\circ} \mathrm{C}$. Lean tissue was trimmed of skin, bone, visible fat and connective tissue. The remaining meat was then minced twice using a MGB-120 meat chopper with a 5-mm (inner diameter) holes plate (YEEKAI, Guangdong, China). The minced meat was packaged and stored at $-18^{\circ} \mathrm{C}$ until use. The manipulations were performed at $4^{\circ} \mathrm{C}$.

\subsection{Methods}

\subsubsection{Manufacture of Pork Sausages}

Trimmed lean tissue and fresh pork back fat were mixed at a ratio of 85 to $15(\mathrm{w} / \mathrm{w}) .0 .02 \mathrm{~g}$ ginger powder, $0.02 \mathrm{~g}$ white pepper and $0.01 \mathrm{~g}$ sodium nitrite $/ 100 \mathrm{~g}$ meat mixture were added, and then ground using a chopper. Four samples were prepared: A: control, $1.5 \mathrm{~g} \mathrm{NaCl}$ and $0.5 \mathrm{~g} \mathrm{KCl} / 100 \mathrm{~g}$ meat mixture; B: $0.6 \mathrm{~g}$ Lys, $1.5 \mathrm{~g} \mathrm{NaCl}$ and $0.5 \mathrm{~g} \mathrm{KCl} / 100 \mathrm{~g}$ meat mixture; C: $0.6 \mathrm{~g}$ Arg, $1.5 \mathrm{~g} \mathrm{NaCl}$ and $0.5 \mathrm{~g} \mathrm{KCl} / 100 \mathrm{~g}$ meat mixture; $\mathrm{D}: 2.0 \mathrm{~g} \mathrm{NaCl}$ and $0.4 \mathrm{~g}$ phosphate compound (the ratio of sodium tripolyphosphate, sodium pyrophosphate and sodium hexametaphosphate is $2: 2: 1) / 100 \mathrm{~g}$ meat mixture. Sample D is similar to the commercial product in China. The meat mixture was fully mixed for another $5 \mathrm{~min}$, and then kept at $4^{\circ} \mathrm{C}$ for $24 \mathrm{~h}$. About $20 \mathrm{~g}$ of the meat mixture was stuffed into a polyethylene casing (diameter: $15 \mathrm{~mm}$ ). The raw sausages were cooked at $80 \pm 2^{\circ} \mathrm{C}$ in a water bath for 30 min. After cooling with tap water, the sausages were stored at $4^{\circ} \mathrm{C}$ for next analysis.

\subsubsection{Cooking Loss (CL) and Water Holding Capacity (WHC)}

$\mathrm{CL}$ and WHC were carried out according to the previous procedure with some modifications [10]. CL was expressed as a percentage based on the raw stuffed net weight. WHC was expressed as the ratio of gel weight after centrifugation $\left(1,000 \times \mathrm{g}\right.$ and $4^{\circ} \mathrm{C}$ for $\left.10 \mathrm{~min}\right)$ to the initial gel sample weight. Each sample was measured four times $(n=4)$.

\subsubsection{Texture Profile Analysis (TPA)}

TPA was performed using a TA-XT plus Texture Analyzer (Stable Micro System Co., Surrey, UK) at room temperature [11]. The samples were compressed twice using a cylindrical 6 probe (P/36R, stainless steel, Stable Micro System Co.) with a trigger-type button set to a pre-test speed of $2.0 \mathrm{~mm} / \mathrm{s}$, a test speed of $1.0 \mathrm{~mm} / \mathrm{s}$, a post-test speed of $1.0 \mathrm{~mm} / \mathrm{s}$, a distance of $4.0 \mathrm{~mm}$ and a trigger force of $0.05 \mathrm{~N}$. The samples were cut into $2 \mathrm{~cm}$ lengths. Each sample was measured six times $(\mathrm{n}=6)$.

\subsubsection{Measurement of Color}

The color was measured using the Hunter scale with an automatic colorimeter WSF (instrument physical optics instrument Co., Ltd, Shanghai, China) [12]. The samples were cut into $0.5 \mathrm{~cm}$ lengths, then immediately analyzed. Each sample was measured four times $(n=4)$.

\subsubsection{Phosphorus (P) and Sodium (Na) Measurement}

$\mathrm{P}$ content and $\mathrm{Na}$ content were determined by a colorimetric method [13]. Each sample was performed in triplicate $(n=3)$.

P content: The samples were dried in a forced-air oven at $105^{\circ} \mathrm{C}$ until their weights were constant. About $0.2 \mathrm{~g}$ sample was taken into the triangle bottle. To the sample, $15 \mathrm{ml}$ nitric acid, $2 \mathrm{ml}$ perchloric acid and $2 \mathrm{ml}$ sulphuric acid were added and mixed uniformly. Nitration reaction was performed by heating on an electric furnace. Na content: The samples were dried under the conditions mentioned above. Na content was determined by an atomic absorption spectrometry (PE Company, AA800, America).

\subsubsection{Sensory Evaluation}

Sensory scores were obtained according to the previous procedure with some modifications [14]. A sensory panel consisted of 10 food science and engineering-majored master graduate student whose ages ranged from 22 to 25 years ( 4 males and 6 females). All participants signed a consent form agreeing to voluntarily participate in the sensory analysis. No information about the products was provided to the consumers in any case. They were asked to express their opinion of the color, flavor, taste, slice traits of the product. All data were recorded on a questionnaire designed to indicate the degree of likeability for each sample using a non-structured scoring scale of ten points, the scoring criteria were shown as follows: 10 to $8=$ like extremely, owning typical flavor characteristics of pork sausage; 5 to $7=$ neither like nor dislike, substantially owning typical flavor characteristics of pork sausage, having apparent "general defects"; 4 to $0=$ dislike extremely, without typical flavor characteristics of pork sausage, having serious "general defects" or slight "serious defects". Also, the overall acceptabilities of pork sausage samples were determined according to color (0.3), flavor (0.2), taste (0.3) and slice traits $(0.2)$. The pork sausage samples were stored under refrigeration $\left(4 \pm 1^{\circ} \mathrm{C}\right)$ until the moment of evaluation to the panelists. Three samples for each treatment were coded with random numbers. All the sensory evaluations were carried out at room temperature under natural light.

\subsubsection{Scanning Electron Microscopy (SEM)}

Microstructure was determined according to the previous protocol with some modifications [8]. Firstly, the gel $(5 \times 5 \times$ $1 \mathrm{~mm}$ ) was dried for nearly $24 \mathrm{~h}$ in an FD-1A-50 lyophilizer (Beijing, Beijing Boyikang Experimental Instrument Co., Ltd. China). Secondly, the SEM observations were performed with a scanning electron microscope (Jeol, JSM 6490LV, Tokyo, Japan). At least three fields from each sample were examined, and one was presented $(n=3)$.

\subsection{Statistical Analysis}

Data were assessed by ANOVA, means and standard errors 
were determined using Excel (Microsoft Office 2010). A $\mathrm{p}<0.05$ significance level was used to determine the differences between the samples.

\section{Results and Discussion}

\subsection{CL and $\mathrm{WHC}$}

As illustrated in Figure 1A, the CL decreased from 16.81\% to $3.19 \%$ or $3.57 \%$ when Lys or Arg was added, respectively $(\mathrm{p}<0.05)$. The CL was not obviously different between the

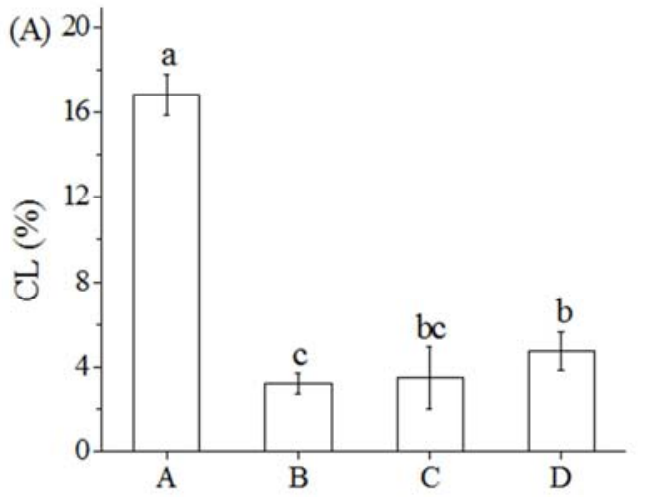

sample treated with Lys or Arg, respectively ( $\mathrm{p}>0.05)$. Similarly, it was reported that (a) either Lys or Arg caused in the obvious decreases in the $\mathrm{CL}$ of pork sausage with $2.5 \mathrm{~g}$ $\mathrm{NaCl} / 100 \mathrm{~g}$, and (b) $1.0 \mathrm{~g} \mathrm{Arg} / 100 \mathrm{ml}$ increased the cooking yield of fresh shrimp [6, 8-9]. Also, the CL decreased to $4.75 \%$ when $0.4 \%$ phosphate compound was added $(\mathrm{p}<0.05)$. The sample treated with Lys had lower CL, while the one treated with Arg had comparative CL, compared with the sample treated with phosphate compound.

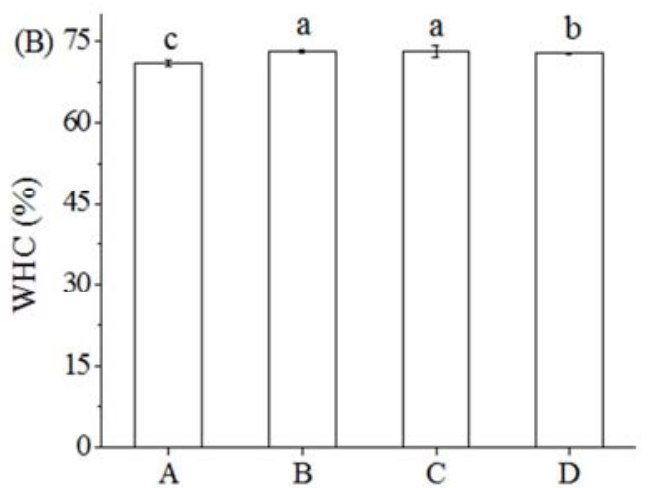

Figure 1. Effects of Lys, Arg or phosphates on the CL (A) and (B) WHC of pork sausage (n=4). Sample A: control, $1.5 \mathrm{~g} \mathrm{NaCl}$ and $0.5 \mathrm{~g} \mathrm{KCl;} \mathrm{Sample} \mathrm{B:} 0.6 \mathrm{~g}$ Lys, $1.5 \mathrm{~g} \mathrm{NaCl}$ and $0.5 \mathrm{~g} \mathrm{KCl}$; Sample C: $0.6 \mathrm{~g} \mathrm{Arg}, 1.5 \mathrm{~g} \mathrm{NaCl}$ and $0.5 \mathrm{~g} \mathrm{KCl}$; and Sample D: $2.0 \mathrm{~g} \mathrm{NaCl}$ and $0.4 \mathrm{~g}$ phosphate compound. Different letters $(a-c)$ mean that the $C L$ and WHC are significantly different among the different samples $(p<0.05)$.

Lys, Arg or phosphate compound significantly increased the WHC $(\mathrm{p}<0.05)$, compared with the control (Figure 1B). Moreover, both Lys and Arg were more effective in improving the WHC than phosphate compound ( $p>0.05$ ). Similarly, the previous literatures also showed that Lys or Arg at $0.8 \mathrm{~g} / 100 \mathrm{~g}$ increased the WHC of pork sausage with $2.5 \mathrm{~g} \mathrm{NaCl} / 100 \mathrm{~g}$ [8-9].

Both Lys and Arg are confirmed to increase the solubility of porcine myosin, which may be responsible for the declined CL as well as the elevated WHC [15-16]. The CL and WHC of meat products are related to its yield and juiciness [10]; therefore, the present results suggest that both Lys and Arg are favorable to improve the yield and juiciness of meat products.

\subsection{Texture}

Texture is a critical characteristic of meat products in terms of consumer acceptability [17]. As shown in Table 1, the addition of Lys or Arg caused significant increases in the hardness, cohesiveness and chewiness $(p<0.05)$, but springiness increases is not significantly ( $p>0.05)$, compared with the control. The textural parameters (hardness, springiness, cohesiveness and chewiness) were not significantly different between the sample treated with Lys or Arg, respectively $(p>0.05)$. The sample treated with phosphate compound had the significantly higher hardness, springiness, cohesiveness and chewiness than the control $(\mathrm{p}<0.05)$. The sample treated with Lys had the equal even higher textural parameters than the one treated with phosphate compound $(\mathrm{p}<0.05)$. Except springiness, the sample treated with Arg had the equal even higher textural parameters than the one treated with phosphate compound $(\mathrm{p}<0.05)$. The present results suggest that the texture of sodium-reduced and low phosphate meat products may be modified by adding Lys or Arg.

Table 1. Effects of Lys, Arg or phosphates on the TPA of pork sausage.

\begin{tabular}{lllll}
\hline Sample & Hardness (N) & Springiness & Cohesiveness & Chewiness (N) \\
\hline A & $21.98 \pm 1.57^{\mathrm{c}}$ & $0.81 \pm 0.014^{\mathrm{b}}$ & $0.51 \pm 0.025^{\mathrm{c}}$ & $9.09 \pm 1.12^{\mathrm{b}}$ \\
B & $27.79 \pm 1.22^{\mathrm{a}}$ & $0.83 \pm 0.008^{\mathrm{ab}}$ & $0.59 \pm 0.038^{\mathrm{ab}}$ & $13.41 \pm 1.59^{\mathrm{a}}$ \\
C & $26.03 \pm 1.48^{\mathrm{a}}$ & $0.82 \pm 0.02^{\mathrm{b}}$ & $0.63 \pm 0.037^{\mathrm{a}}$ & $13.16 \pm 1.10^{\mathrm{a}}$ \\
D & $23.69 \pm 0.71^{\mathrm{b}}$ & $0.84 \pm 0.008^{\mathrm{a}}$ & $0.58 \pm 0.02^{\mathrm{b}}$ & $11.67 \pm 1.25^{\mathrm{a}}$ \\
\hline
\end{tabular}

Sample A: control, $1.5 \mathrm{~g} \mathrm{NaCl}$ and $0.5 \mathrm{~g} \mathrm{KCl}$; Sample B: $0.6 \mathrm{~g}$ Lys, $1.5 \mathrm{~g} \mathrm{NaCl}$ and $0.5 \mathrm{~g} \mathrm{KCl}$; Sample C: $0.6 \mathrm{~g} \mathrm{Arg}$, $1.5 \mathrm{~g} \mathrm{NaCl}$ and $0.5 \mathrm{~g} \mathrm{KCl}$; and Sample D: $2.0 \mathrm{~g} \mathrm{NaCl}$ and 0.4 $\mathrm{g}$ phosphate compound. Values represent the average $\pm \mathrm{SD}$, $\mathrm{n}=6$. Different letters in the same column are significantly different among the different samples $(\mathrm{p}<0.05)$.

Some literatures have showed that both Lys and Arg can increase the solubility, the surface hydrophobic residues and active sulfhydryl group of porcine myosin [16-17], and enhance the strength of chicken salt-soluble proteins gel [18]. In addition, the addition of Lys or Arg is also favorable to form an even and compact pork sausage [8-9]. These may contribute to the increased TPA parameters.

\subsection{Color}

Compared with the control, the addition of Lys, Arg or phosphate compound caused the obvious decreases in the $L^{*}$ 
values $(\mathrm{p}<0.05)$ (Figure $2 \mathrm{~A})$. This was consistent to the previous findings [8-9]. The $L^{*}$ values did not significantly differ among the samples treated with Lys, Arg and phosphate compound, respectively $(\mathrm{p}>0.05)$. The $L^{*}$ value is positively correlated to the lightness; therefore, the results suggest that the addition of Lys or Arg may generate a darker meat products. The changes in $L^{*}$ values were negatively related to the moisture of meat products [19]. As mentioned above, the addition of Lys, Arg or phosphate compound caused the decreases in CL (higher moisture), may contribute to the decreased $L^{*}$ values.
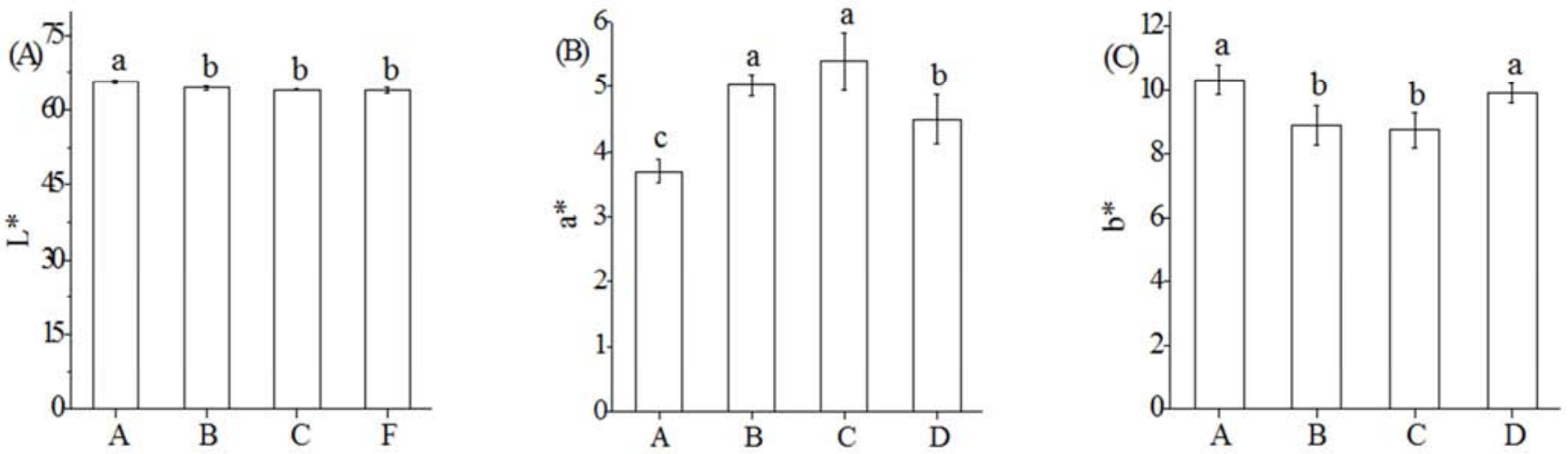

Figure 2. Effects of Lys, Arg or phosphates on the color of pork sausage ( $n=4)$. (A) $L^{*}$ values, (B) $a^{*}$ values and (C) $b^{*}$ values. Sample A: control, $1.5 \mathrm{~g} \mathrm{NaCl}$ and $0.5 \mathrm{~g} \mathrm{KCl}$; Sample B: $0.6 \mathrm{~g} \mathrm{Lys,} 1.5 \mathrm{~g} \mathrm{NaCl}$ and $0.5 \mathrm{~g} \mathrm{KCl}$; Sample C: $0.6 \mathrm{~g} \mathrm{Arg,} 1.5 \mathrm{~g} \mathrm{NaCl}$ and $0.5 \mathrm{~g} \mathrm{KCl}$; and Sample D: $2.0 \mathrm{~g} \mathrm{NaCl}$ and $0.4 \mathrm{~g}$ phosphate compound. Different letters $(a-c)$ mean that the color are significant different among the different samples $(p<0.05)$.

Compared with the control, the addition of Lys, Arg or phosphate compound increased $a^{*}$ values $(\mathrm{p}<0.05)$ (Figure 2B). Furthermore, the sample treated with Lys or Arg had higher $a^{*}$ values than the one treated with phosphate compound $(\mathrm{p}<0.05)$. The similar phenomena were also observed: (a) Lys or Arg increased $a^{*}$ values of pork sausage with $2.5 \mathrm{~g} \mathrm{NaCl} / 100 \mathrm{~g}$ sausage [8-9], and (b) shrimps treated with Lys or Arg showed reddish color after thawing [6]. The $a^{*}$ value is positively correlated to the redness; therefore, the present results suggest that the addition of Lys/Arg may generate redder meat products. This is in agreement with sensory color (Figure 3 ).

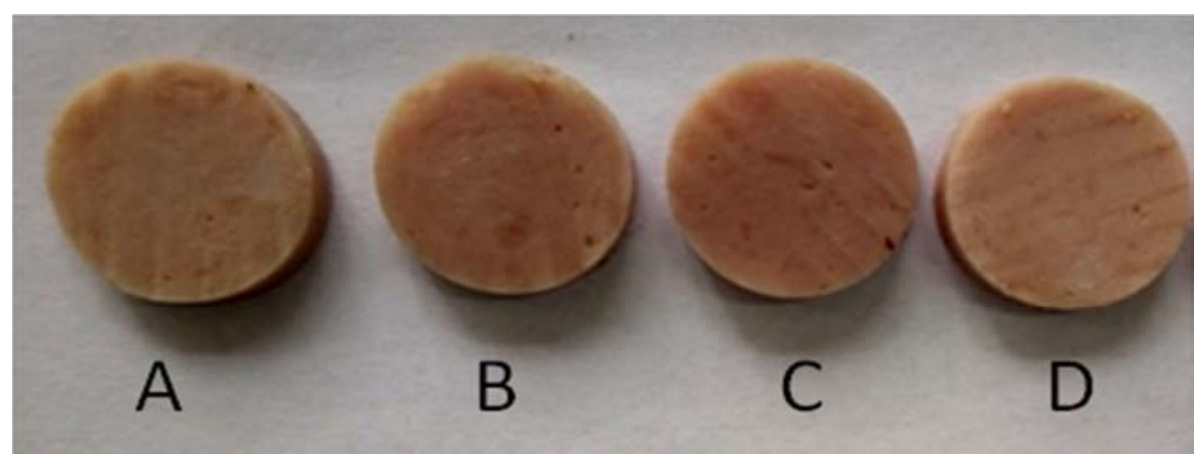

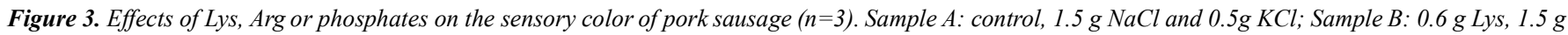
$\mathrm{NaCl}$ and $0.5 \mathrm{~g} \mathrm{KCl}$; Sample C: $0.6 \mathrm{~g} \mathrm{Arg}, 1.5 \mathrm{~g} \mathrm{NaCl}$ and $0.5 \mathrm{~g} \mathrm{KCl}$; and Sample D: $2.0 \mathrm{~g} \mathrm{NaCl}$ and $0.4 \mathrm{~g}$ phosphate compound.

As illustrated in Figure 2C, Lys or Arg significantly decreased $b^{*}$ values $(\mathrm{p}<0.05)$, while phosphate compound resulted in the slight declines in $b^{*}$ values $(\mathrm{p}>0.05)$, compared with the control. The $b^{*}$ value is positively correlated to the yellowness; therefore, the results suggest that the addition of Lys/Arg may produce less yellow meat products. This is consistent to the sensory color (Figure 3).

The redness and yellowness in meat products are usually related to the chemical state of iron ion in the central porphyrin ring of chromoproteins. Lys and Arg have an antioxidant activity and coordination capacity with endogenous metallic ions, which may prevent ferroporphyrin from oxidation $[13,20]$. This may contribute to the increased $a^{*}$ values as well as the decreased $b^{*}$ values.

\subsection{P and Na Content}

As shown in Figure 4, it was unexpected that both Lys and Arg increased the P content of pork sausage: the effects of Lys were insignificant $(\mathrm{p}>0.05)$, while those of Arg were significant $(\mathrm{p}<0.05)$. Both Lys and Arg are easy to be oxidized into colored substances, which may interfere with the detection of $\mathrm{P}$ content, ultimately, contributing to the present results [21]. The aldehydes derived from lipid oxidation are able to vary quickly some amino acid residues, such as Lys, ultimately, contributing to the color changes. As expectedly, the addition of phosphate compound caused the significant increases in $P$ content $(\mathrm{p}<0.05)$.

As expectedly, the addition of Lys or Arg had the slight 
influences on the $\mathrm{Na}$ content $(\mathrm{p}>0.05)$. Also, it can be expected that the sample treated with phosphate compound had significantly higher $\mathrm{Na}$ content compared with the other samples $(\mathrm{p}<0.05)$. In $100 \mathrm{~g}$ pork sausage, the sample treated with phosphate compound was about $200 \mathrm{mg} \mathrm{Na}$ higher than the one treated with Lys or Arg, respectively. The possible reason is that to $100 \mathrm{~g}$ meat mixture, the additional $0.5 \mathrm{~g}$ $\mathrm{NaCl}$ and $0.4 \mathrm{~g}$ phosphate compound were added. Considering that an excessive dietary intake of $\mathrm{P}$ and/or $\mathrm{Na}$ poses potential health risks [3-4], the sample treated with Lys or Arg may meet the demands of certain segments of consumers.

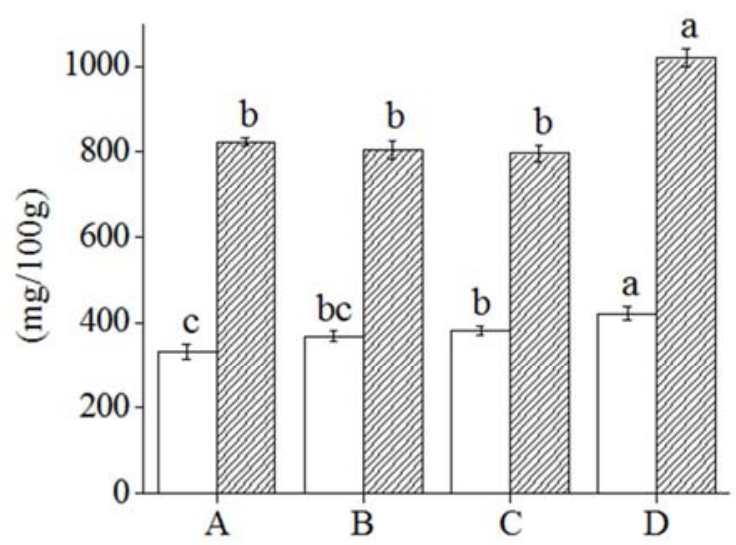

Figure 4. Effects of Lys, Arg, or phosphates on the $P(\square$ and Na ( $\square$ ( content of pork sausage $(n=3)$. Sample A: control, $1.5 \mathrm{~g} \mathrm{NaCl}$ and $0.5 \mathrm{~g} \mathrm{KCl}$; Sample B: $0.6 \mathrm{~g} \mathrm{Lys,} 1.5 \mathrm{~g} \mathrm{NaCl}$ and $0.5 \mathrm{~g} \mathrm{KCl}$; Sample C: $0.6 \mathrm{~g} \mathrm{Arg,} 1.5 \mathrm{~g}$ $\mathrm{NaCl}$ and $0.5 \mathrm{~g} \mathrm{KCl}$; and Sample D: $2.0 \mathrm{~g} \mathrm{NaCl}$ and $0.4 \mathrm{~g}$ phosphate compound. Different letters $(a-c)$ mean that the $N a$ and $P$ are significant different among the different samples $(p<0.05)$.

\subsection{Sensory Quality}

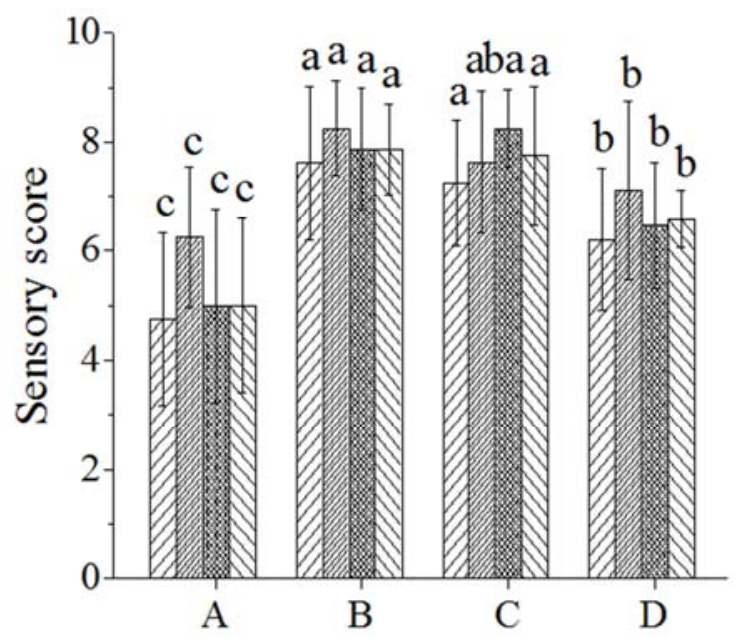

Figure 5. Effects of Lys, Arg or phosphates on the sensory score of pork

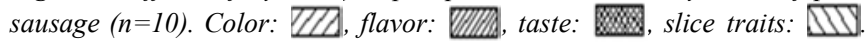
Sample A: control, $1.5 \mathrm{~g} \mathrm{NaCl}$ and $0.5 \mathrm{~g} \mathrm{KCl}$; Sample B: $0.6 \mathrm{~g} \mathrm{Lys,} 1.5 \mathrm{~g}$ $\mathrm{NaCl}$ and $0.5 \mathrm{~g} \mathrm{KCl}$; Sample C: $0.6 \mathrm{~g} \mathrm{Arg}, 1.5 \mathrm{~g} \mathrm{NaCl}$ and $0.5 \mathrm{~g} \mathrm{KCl}$; and Sample D: $2.0 \mathrm{~g} \mathrm{NaCl}$ and $0.4 \mathrm{~g}$ phosphate compound. Different letters ( $\mathrm{a}-\mathrm{c}$ ) mean that the sensory score are significant different among the different samples $(p<0.05)$.

Compared with the control, the sample treated with phosphate compound, especially Lys or Arg had better color based on sensory evaluation $(\mathrm{p}<0.05)$ (Figure 5$)$. The results were in accordance with the sensory color (Figure 3). Lys, Arg or phosphate compound increased the flavor and taste, and Lys and Arg were more effective than phosphate compound $(p<0.05)$. Literature has shown that the addition of $\mathrm{KCl}$ to meat products usually causes undesirable aftertastes such as bitter, metallic and astringent tastes [7]. The results suggest that the addition of Lys or Arg is able to mask the undesirable aftertastes provided by $\mathrm{KCl}$. The sample treated with phosphate compound, especially Lys or Arg, had better slice traits than the control $(\mathrm{p}<0.05)$. The slice was rough and exudative for the control, while smooth and less exudative for the sample treated with phosphate compound, Lys or Arg. Considering that solubilization of myofibrillar proteins is necessary for their gelation [22], the results may be due to the capacity that Lys and Arg have the synergistic solubilization of porcine myofibrillar proteins [15].

\subsection{Microstructure}

The microstructure illustrates the distribution of clusters and caves of meat products, which is relevant to its CL, WHC and texture [23]. Many particles separated from each other were distributed in the control, indicating that a poor three-dimensional network was formed in the absence of Lys/Arg (Figure 6). The possible reason is that the solubility of porcine myofibrillar proteins is low [24], and the solubilized myofibrillar proteins are not enough to form a three-dimensional network which connects meat particles into a whole under the present conditions. Compared with the control, the addition of Lys, Arg or phosphate compound formed a three-dimensional network. This may be due to the fact that Lys, Arg or phosphate compound enhance the solubility of myofibrillar proteins $[16,25]$. The sample treated with Lys or Arg was porous, while the one treated with phosphate compound was relatively compact. Both Lys and Arg reportedly adjusted $\mathrm{pH}$ and increased the solubility of porcine myosin $[8-9,15]$. Also, it is reported that Arg is able to suppress protein aggregation [26]. These properties of Lys/Arg may be responsible for the microstructure of actomyosin gel. The different microstructures may contribute to the different $\mathrm{CL}$ and WHC among the control, the sample treated with Lys, Arg or phosphate compound, respectively.

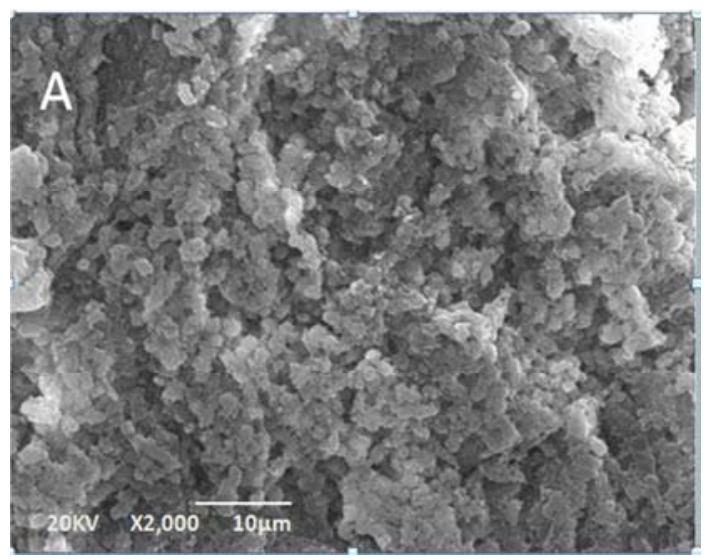



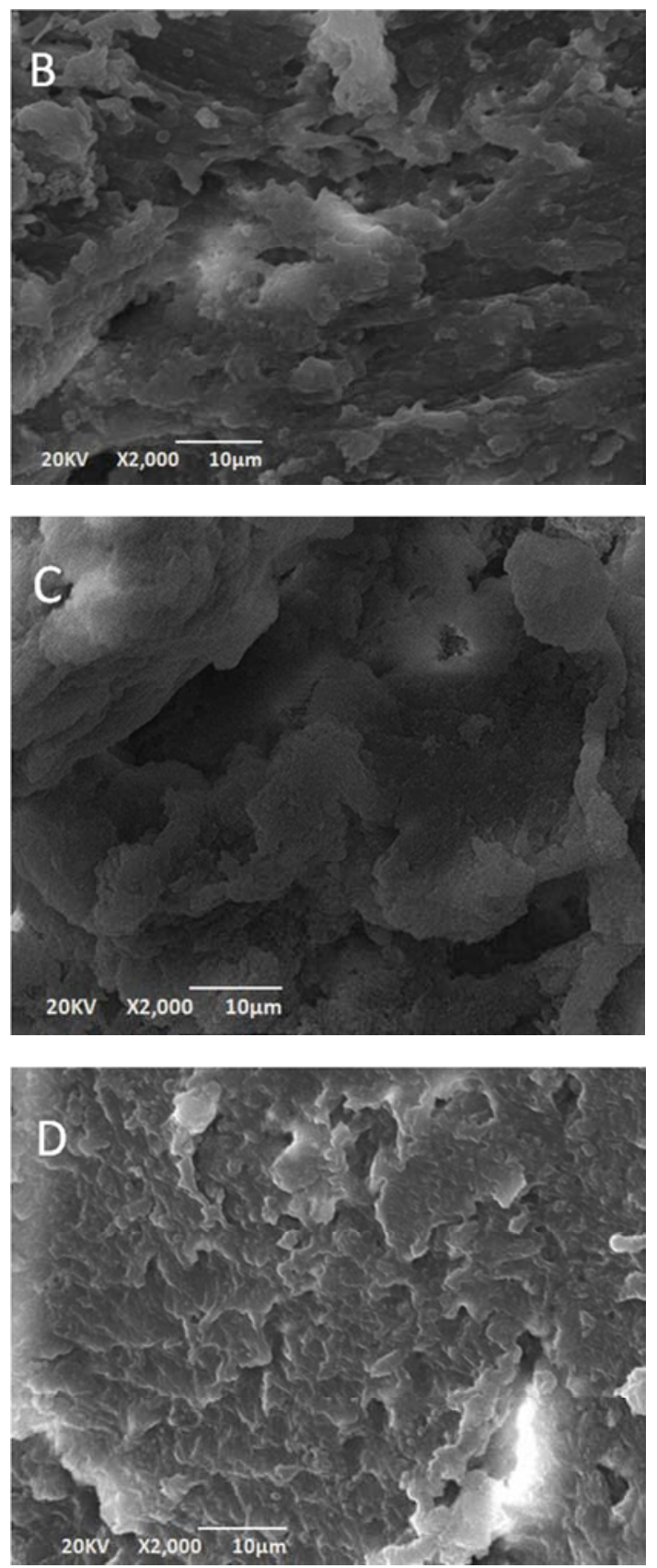

Figure 6. Effects of Lys, Arg or phosphates on SEM images of pork sausage $(\mathrm{n}=3)$. Sample A: control, $1.5 \mathrm{~g} \mathrm{NaCl}$ and $0.5 \mathrm{~g} \mathrm{KCl}$; Sample B: $0.6 \mathrm{~g} \mathrm{Lys,} 1.5$ $\mathrm{g} \mathrm{NaCl}$ and $0.5 \mathrm{~g} \mathrm{KCl}$; Sample C: $0.6 \mathrm{~g} \mathrm{Arg}, 1.5 \mathrm{~g} \mathrm{NaCl}$ and $0.5 \mathrm{~g} \mathrm{KCl}$; and Sample D: $2.0 \mathrm{~g} \mathrm{NaCl}$ and $0.4 \mathrm{~g}$ phosphate compound.

\section{Conclusions}

Lys/Arg was demonstrated to decrease the CL, but increase WHC, textural parameters (hardness, cohesiveness and chewiness), and sensory qualities of sodium-reduced and phosphate-free pork sausage. Also, the addition of Lys/Arg caused the formation of even and compact three-dimensional network. The sample treated with Lys/Arg had better CL, WHC and sensory qualities, but lower $\mathrm{P}$ and $\mathrm{Na}$ content than the commercial one in China, indicating that Lys/Arg had a potential for pork sausage preparation.

\section{Acknowledgements}

This work was supported by the National Natural Science Foundation of China (No. 21542008).

\section{References}

[1] Hurtado, S., Saguer, E., Toldra, M., Pares, D. and Carretero, C. (2012). Porcine plasma as polyphosphate and caseinate replacer in frankfurters. Meat Sci. 90 (3): 624-628.

[2] Totosaus, A. and Pérez-Chabela, M. L. (2009). Textural properties and microstructure of low-fat and sodium-reducedmeat batters formulated with gellan gum and dicationic salts. LWT - Food Sci. Technol. 42 (2): 563-569.

[3] Ruusunen, M. and Puolanne, E. (2005). Reducing sodium intake from meat products. Meat Sci. 70 (3): 531-541.

[4] Sherman, R. A. and Mehta, O. (2009). Dietary phosphorus restriction in dialysis patients: potential impact of processed meat, poultry, and fish products as protein sources. Am. J. Kidney Dis. 54 (1): 18-23.

[5] Sofos, J. N. (1983). Effects of reduced salt $(\mathrm{NaCl})$ levels on the stability of frankfurters. J. Food Sci. 48 (6): 1684-1691.

[6] Wachirasiri, K., Wanlapa, S., Uttapap, D. and V. Rungsardthong. (2016). Use of amino acids as a phosphate alternative and their effects on quality of frozen white shrimps (Penaeus vanamei). LWT - Food Sci. Technol. 69: 303-311.

[7] Santos, B. A., Campagnol, P. C. B., Morgano, M. A. and Pollonio, M. A. R. (2014). Monosodium glutamate, disodium inosinate, disodium guanylate, lysine and taurine improve the sensory quality of fermented cooked sausages with $50 \%$ and $75 \%$ replacement of $\mathrm{NaCl}$ with $\mathrm{KCl}$. Meat Sci. 96 (1): 509-513.

[8] Zhou, C. L., Li, J. and Tan, S. J. (2014a). Effect of L-lysine on the physicochemical properties of pork sausage. Food Sci. Biotechnol. 23 (3): 775-780.

[9] Zhou, C. L., Li, J., Tan, S. J. and Sun, G. J. (2014b). Effects of L-arginine on physicochemical and sensory characteristics of pork sausage. J Food Sci. Technol. 6 (5): 660-667.

[10] Chen, C. G., Wang, R., Sun, G., Fang, H., Ma, D. and S. N. Yi. (2010). Effects of high pressure level and holding time on properties of duck muscle gels containing $1 \%$ curdlan. Innovative Food Sci and Emerg. 11 (4): 538-542.

[11] Ma, F., Chen, C. G., Zheng, L., Zhou, C. L., Cai, K. Z. and Han, Z. (2013). Effect of high pressure processing on the gel properties of salt-soluble meat protein containing $\mathrm{CaCl}_{2}$ and к-carrageenan. Meat Sci. 95 (1): 22-26.

[12] Zhou, C. L., Wang, J., Wang, H., Zhang, L. and Cai, K. Z. (2012). Effect of carboxyhemoglobin on color stability of cooked pork sausage. Food Sci. Biotechnol. 21 (1): 267-272.

[13] Remko, M., Fitz, D. and Rode, B. M. (2008). Effect of metal ions $\left(\mathrm{Li}^{+}, \mathrm{Na}^{+}, \mathrm{K}^{+}, \mathrm{Mg}^{2+}, \mathrm{Ca}^{2+}, \mathrm{Ni}^{2+}, \mathrm{Cu}^{2+}\right.$ and $\left.\mathrm{Zn}^{2+}\right)$ and water coordination on the structure and properties of $\mathrm{L}$-arginine and zwitterionic L-arginine. J. Chem. Phys. 112 (5): 7652-7661.

[14] Meilgaard, M. C., Carr, B. T. and Civille, G. V. (2007). Sensory evaluation techniques. Fourth Edition. Physiol. Behav. 107 (4): 598-605. 
[15] Guo, X. Y., Peng, Z. Q., Zhang, Y. W., Liu, B. and Cui, Y. Q. (2015). The solubility and conformational characteristics of porcine myosin as affected by the presence of L-lysine and L-histidine. Food Chem. 170: 212-217.

[16] Takai, E., Yoshizawa, S., Ejima, D., Arakawa, T. and K. Shiraki. (2013). Synergistic solubilization of porcine myosin in physiological salt solution by arginine. Int. J. Biol. Macromol. 62 (11): 647-651.

[17] Gao, X, Q., Zhang, W. G. and Zhou, G. H. (2014). Effects of glutinous rice flour on the physiochemical and sensory qualities of ground pork patties. LWT-Food Sci and Technol. 58: $135-141$.

[18] Qin, H., Xu, P., Zhou C. L. and Wang, Y. J. (2015). Effects of L-arginine on water holding capacity and texture of heat-induced gel of salt-soluble proteins from breast muscle. LWT-Food Sci. Technol. 63 (2): 912-918.

[19] Hong, G. P., Park, S. H., Kim, J. Y. and Min, S. G. (2006). The effects of high pressure and various binders on the physicochemical properties of restructured pork meat. Asian Austral. J. Anim. 19 (10): 1484-1489.

[20] Vasilescu, M., Voicescu, M., Lemmetyinen, H. and A. Meghea. (2004). The oxidative activity of riboflavin studied by luminescence methods: the effect of cysteine, arginine, lysine and histidine amino acids. Rev. Roum. Chim. 51 (7): 683-690.
[21] Goel, A. (2012). A kinetic and mechanistic study on the oxidation of arginine and lysine by hexacyanoferrate (III) catalysed by iridium (III) in aqueous alkaline medium. J. Indian Chem Soc. 3 (1): 1191-1196.

[22] Lin, T. M. and Park, J. W. (1998). Solubility of salmon myosin as affected by conformational changes at various ionic strengths and pH. J. Food Sci. 63 (2): 215-218.

[23] Han, M. Y., Wang, P., Xu, X. L. and Zhou, G. H. (2014). Low-field NMR study of heat-induced gelation of pork myofibrillar proteins and its relationship with microstructural characteristics. Food Res. Int. 62: 1175-1182.

[24] Sun, X. D. and Holley, R. A. (2011). Factors influencing gel formation by myofibrillar proteins in muscle foods. Food Sci. $10(1): 33-51$.

[25] Xiong, Y. L. (2005). Role of myofibrillar proteins in water-binding in brine-enhanced meats. Food Res. Int. 38 (3): 281-287.

[26] Lyutova E M., Kasakov A S. and Gurvits B Y. (2007). Effects of arginine on kinetics of protein aggregation studied by dynamic laser light scattering and tubidimetry techniques.[J]. Biotechnol. Prog. 23 (6): 1411-1416. 